\title{
Flexural behaviour of ferrocement roof panels
}

\author{
A. S. Alnuaimi, A. Hago \& K. S. Al-Jabri \\ Department of Civil and Architectural Engineering, \\ Sultan Qaboos University, Sultanate of Oman
}

\begin{abstract}
This paper presents the experimental results of nine roof panels made of Ferrocement. Two types of channel sections and one type of box section were tested. All panels were $2 \mathrm{~m}$ long, $470 \mathrm{~mm}$ wide and $20 \mathrm{~mm}$ thick. Channel type A had side edge beams $95 \mathrm{~mm}$ deep and channel type B had side edge beams $50 \mathrm{~mm}$ deep. The depth of the box section was $95 \mathrm{~mm}$. Thin hexagonal wire mesh was used as reinforcement. The number of wire mesh layers was varied between two to six. The wires were impregnated midway through the thickness of the panels. The panels were tested for bending moment with simple supports. The main variables studied were the number of wire mesh layers, the cross sectional shape of the panel and the depth of edge beam. Tests revealed that all panels showed acceptable strength for roofing systems. The increase in the number of wire mesh layers leads to an increase in the flexural strength. The box section showed strength similar to that of the channel section with $95 \mathrm{~mm}$ edge beam. The channels with $50 \mathrm{~mm}$ deep edge beams showed strength much less than the ones with $95 \mathrm{~mm}$ edge beam and box section.

Keywords: Ferrocement, fibre reinforcement, slab panels, bending, box section panels, channel panels.
\end{abstract}

\section{Introduction}

Ferrocement is a type of thin wall reinforced concrete commonly constructed of hydraulic cement mortar reinforced with completely infiltrated, closely spaced layers of continuous and relatively small size wire mesh. In its role as a thin reinforced concrete product and as laminated cement-based composite, Ferrocement has found itself in several applications both in new structures and repair and rehabilitation of existing structures. This includes all building members like walls, roofs, columns, beams etc. Compared with the conventional 
reinforced concrete, Ferrocement is reinforced in orthogonal directions; therefore, it has homogenous properties in two directions. Ferrocement's low cost, durability and serviceability were recognized by engineers and builders throughout the world. It is frequently used for the construction of housing and buildings, landscape structures, agricultural facilities, public health facilities and transportation.

In developing countries, the most critical components in dwelling construction are appropriate roofing, walls and floors. The use of local materials has not been very successful in producing durable and resistant to fire, insects, and flood or earthquake roofing materials. As a result, many developing countries import expensive galvanised iron sheets or use hazardous asbestos cement sheets as roofing material. Ferrocement appears to be an economical alternative material for roofing $[1,2]$.

The use of Ferrocement as roofing and slab elements has been a subject of investigation by many researchers. For roofing, Ferrocement has been used for channel type section, folded plates, ribbed slabs, cylindrical shells, circular domes, funicular shells etc [3]. The use of hollow box section as a roofing element has been investigated by Mathews et al. [4]. A total of 21 Ferrocement box sections have been tested under symmetrical line loads applied at one third span points. The test results confirm that the Ferrocement box hollow sections have adequate strength, stiffness and other serviceability requirements for residual applications. Also the theoretical values of cracking load, ultimate load, deflection and crack width at working load showed good agreement with experimental values. Kenai and Brooks [5] carried out extensive testing on direct tensile, four point flexural and drop impact tests on specimens reinforced with steel wire meshes (13 and $25 \mathrm{~mm}$ thick) with varied amounts. They used a simple model based on plastic analysis which was originally proposed by Mansour and Paramasivam [6]. The model employed a rectangular stress block in the compression zone and the neutral axis depth was calculated by considering the equilibrium of tension and compression forces. The ultimate moment was calculated by multiplying any one of the two forces by the lever arm. Such models cannot be used in cases where the reinforcing mesh is dispersed in the middle of the slab. This is because of the small thickness of the Ferrocement slab panels (about 20mm) which makes it practically difficult to control the uniform dispersion of the wire mesh through the depth. Ahmed et al. [7] studied the shear behaviour of Ferrocement channel beams. Their results indicated that cracking load and ultimate shear strength increase with the increase in the volume of wire mesh and mortar strength and decrease with the increase of shear span/depth ratio. Al-Kubaisy and Jummat [8] investigated the use of Ferrocement in improving the behaviour of reinforced concrete slabs. The tension zone of each slab was covered with Ferrocement layer. They studied the effects of the percentage of wire mesh reinforcement in the Ferrocement cover layer, thickness of Ferrocement layer and the type of connection between the Ferrocement layer and the reinforced concrete slab on the ultimate flexural load, first crack load, crack width and spacing, and load-deflection relationship. They concluded that the use of Ferrocement cover slightly increases the ultimate 
flexural load and increases the first crack load. Considerable reduction in crack widths and spacing was observed with specimen with Ferrocement layers. The performance of Ferrocement panels under normal, moderate and hostile environments was investigated by Masood et al. [9]. They concluded that the flexural capacity of the panel increases with the addition of fly ash. Considerable deterioration of wire meshes fabric was observed due to sustained exposure in saline casting and curing condition. Recently, Hago et al. [10] conducted 6 experimental tests to study the ultimate and service behaviour of Ferrocement roof slab panels. The parameters studied include: the effect the effect of the percentage of wire mesh reinforcement by volume and the structural shape of the panels on the ultimate flexural strength, first crack load, crack spacing and loaddeformation behaviour. The results demonstrated that the monolithic shallow edge Ferrocement beams with the panels considerably improves the service and ultimate behaviour, irrespective of the steel layers used. Also, slabs with channel sections supported larger ultimate loads and behaved better under service loads than their flat slabs counterparts. Due to large deflections experienced by the thin panels, large deflection theory was adopted in the analysis. Good agreement was obtained between the theoretical and experimental ultimate loads using the proposed mathematical model.

In this research, nine simply supported slab panels were tested for flexure. The specimens were arranged in three categories based on the cross-section: channel section type A, channel section type B and box section. The aim was to study the effects of the shape of cross-section and the number of wire mesh layers on the behaviour and ultimate capacity of the tested panels. The panels were constructed manually in a simple manner, so similar panels can be constructed and used as roofing system with almost no equipment needed.

\section{Test program}

The experimental investigation consisted of fabricating and testing, for flexure, nine Ferrocement roof panels. All panels were $20 \mathrm{~mm}$ thick and were reinforced with thin steel wire meshes sandwiched midway through the thickness. The panels were divided into three groups according to their shape and number of wire mesh layers (Table 1). The first group, Channel A, consisted of three channel-shaped panels. The dimensions were $470 \mathrm{~mm}$ outer widths and $2100 \mathrm{~mm}$ length with two edge beams $95 \mathrm{~mm}$ deep (Figure 1). The second group, Channel $\mathrm{B}$, consisted of three channel-shaped panels similar to the first group except that the edge beam was $50 \mathrm{~mm}$ deep (Figure 2). The third group consisted of three box section panels with $470 \mathrm{x} 95 \mathrm{~mm}$ outer cross section and $2100 \mathrm{~mm}$ total length. The hollow core was $430 \times 55 \mathrm{~mm}$ as shown in Figure 3. In all tested panels, the test span was the middle $600 \mathrm{mmm}$ of the span.

\section{Material used}

Ordinary Portland cement and natural sand were used in making the Ferrocement concrete in the ratio of 1:2 respectively with a water to cement ratio of 0.55 . The 
average mortar cube compressive strength was $47.1 \mathrm{~N} / \mathrm{mm}^{2}$ and the average prism flexural strength was $5.23 \mathrm{~N} / \mathrm{mm}^{2}$ (Table 1). For reinforcement, a hexagonal wire mesh with closely spaced wires was used in the tested panels. The wire mesh had a diameter of $0.579 \mathrm{~mm}$ and a spacing of $12.13 \mathrm{~mm}$ in both directions. The number of wire mesh layers varied from two layers to six layers. The wire mesh was stretched on a frame of $6 \mathrm{~mm}$ steel bars having yield strength of $250 \mathrm{~N} / \mathrm{mm}^{2}$ (Figures 1-3). The cement, sand and water were mixed using a power driven drum mixer for about five minutes. The mortar was designed to give 28 day strength of about $40 \mathrm{~N} / \mathrm{mm}^{2}$. Wooden moulds were used to cast the slabs. A layer of mortar of about $10 \mathrm{~mm}$ thick was first placed in the mould followed by the reinforcement cage and then a second layer of mortar was placed to make the required thickness. Due to the small thickness of the panel, the wire mesh was placed almost at mid thickness. With each panel, six $100 \mathrm{~mm}$ cubes and two prisms were cast to determine the mortar compressive strength and modulus of rupture. After one day of casting, the panels and cubes were removed from the moulds and were kept under wet Hessian cloth until the day of testing which was about 28 days from the date of casting.

Table 1: $\quad$ Models tested and their material properties.

\begin{tabular}{|c|c|c|c|c|c|c|}
\hline $\begin{array}{c}\text { Model } \\
\text { No. }\end{array}$ & $\begin{array}{c}\text { Dimensions } \\
(\mathrm{mm})\end{array}$ & $\begin{array}{c}\text { Depth of } \\
\text { edge beam } \\
(\mathrm{mm})\end{array}$ & $\begin{array}{c}\text { No. of } \\
\text { steel } \\
\text { layers }\end{array}$ & $\begin{array}{c}\text { \% Volume } \\
\text { of steel }\end{array}$ & $\begin{array}{c}\text { Compressive } \\
\text { strength } \\
\left(\mathrm{N} / \mathrm{mm}^{2}\right)\end{array}$ & $\begin{array}{l}\text { Flexural } \\
\text { strength } \\
\left(\mathrm{N} / \mathrm{mm}^{2}\right)\end{array}$ \\
\hline Ch2-A & $2100 \times 470 \times 20$ & 95 & 2 & 1.36 & 54.9 & 5.0 \\
\hline Ch4-A & $2100 \times 470 \times 20$ & 95 & 4 & 1.60 & 46.0 & 4.8 \\
\hline Ch6-A & $2100 \times 470 \times 20$ & 95 & 6 & 1.76 & 47.5 & 4.6 \\
\hline Ch2-B & $2100 \times 470 \times 20$ & 50 & 2 & 1.36 & 42.6 & 6.6 \\
\hline Ch4-B & $2100 \times 470 \times 20$ & 50 & 4 & 1.57 & 40.6 & 6.8 \\
\hline Ch6-B & $2100 \times 470 \times 20$ & 50 & 6 & 1.77 & 42.0 & 6.6 \\
\hline Box1 & $2100 \times 470 \times 20$ & 95 & 2 & 1.24 & 44.1 & 5.3 \\
\hline Box2 & $2100 \times 470 \times 20$ & 95 & 4 & 1.43 & 31.0 & 5.5 \\
\hline Box3 & $2100 \times 470 \times 20$ & 95 & 6 & 1.62 & 54.6 & 7.2 \\
\hline
\end{tabular}

\section{Test procedure}

All slabs were tested for flexure. They were simply supported with a clear span of $2000 \mathrm{~mm}$ and test span of $600 \mathrm{~mm}$ in mid-span. The load was applied as two symmetrically arranged concentrated loads, using a spreader steel beam and a 5ton hydraulic jack. The load was measured using an electric load cell of $50 \mathrm{kN}$ capacity and was applied in increments of $0.5 \mathrm{kN}$. The slabs were painted using white emulsion to assist in detecting the cracks. Deflection under the centre of the slab was measured using Linear Variable Displacement Transducers (LVDT). The load cell and LVDT were connected to a data acquisition system. Surface concrete strains were measured using a digital DEMEC gauges. At each load increment, careful search was made for cracks on all sides of the slab with the aid of a magnifying glass and a powerful electric lamp. The crack spacing, 
the number of cracks, the extent of the cracked zone over the length of the slab and the ultimate load were all noted. The failure load considered in this investigation was the load value after which the panel ceases to resist additional load or the load measured just before sudden collapse. Figure 4 shows typical tested panel.

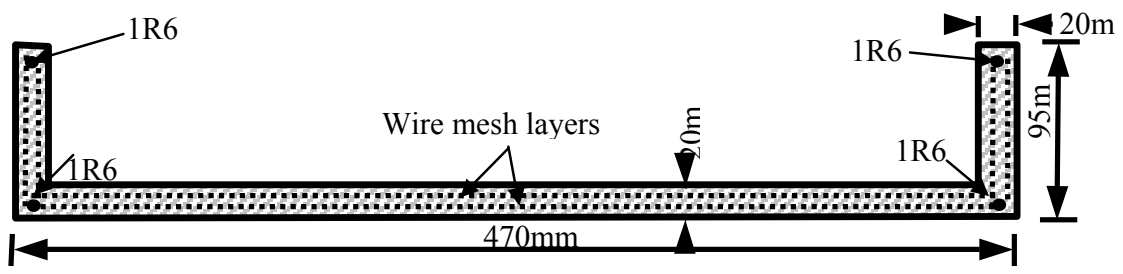

Figure 1: $\quad$ Channel type A section, Ch A.

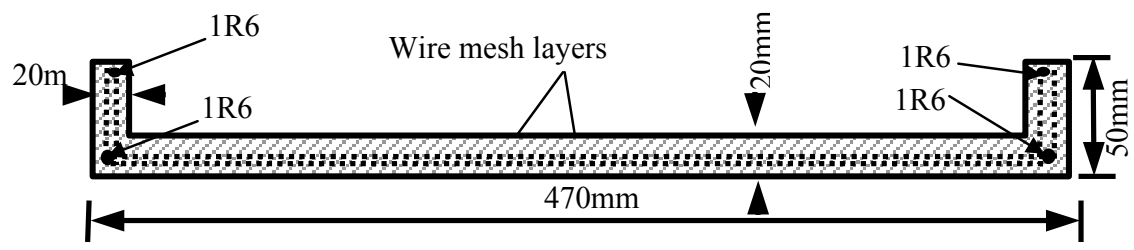

Figure 2: $\quad$ Channel type B section, Ch B.

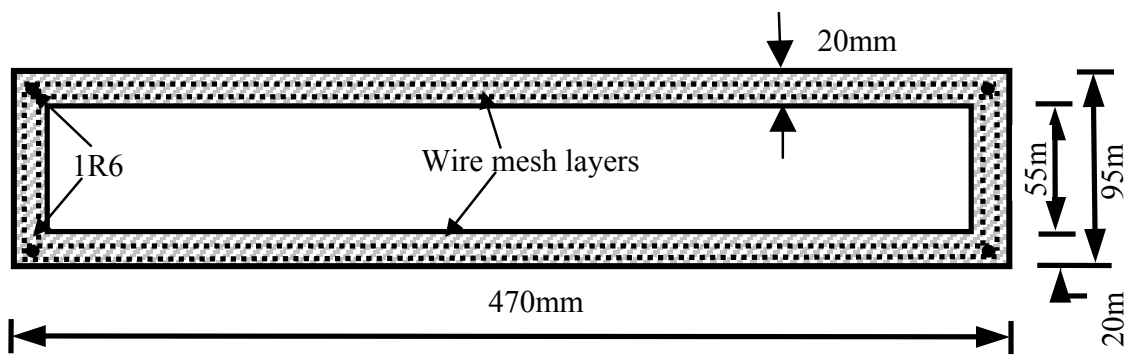

Figure 3: $\quad$ Box B section, Box.

Along with each panel, six 100x100x100mm cubes were tested for compressive strength and two $100 \times 100 \times 500 \mathrm{~mm}$ prisms were tested for modulus of rupture. 
98 High Performance Structures and Materials III

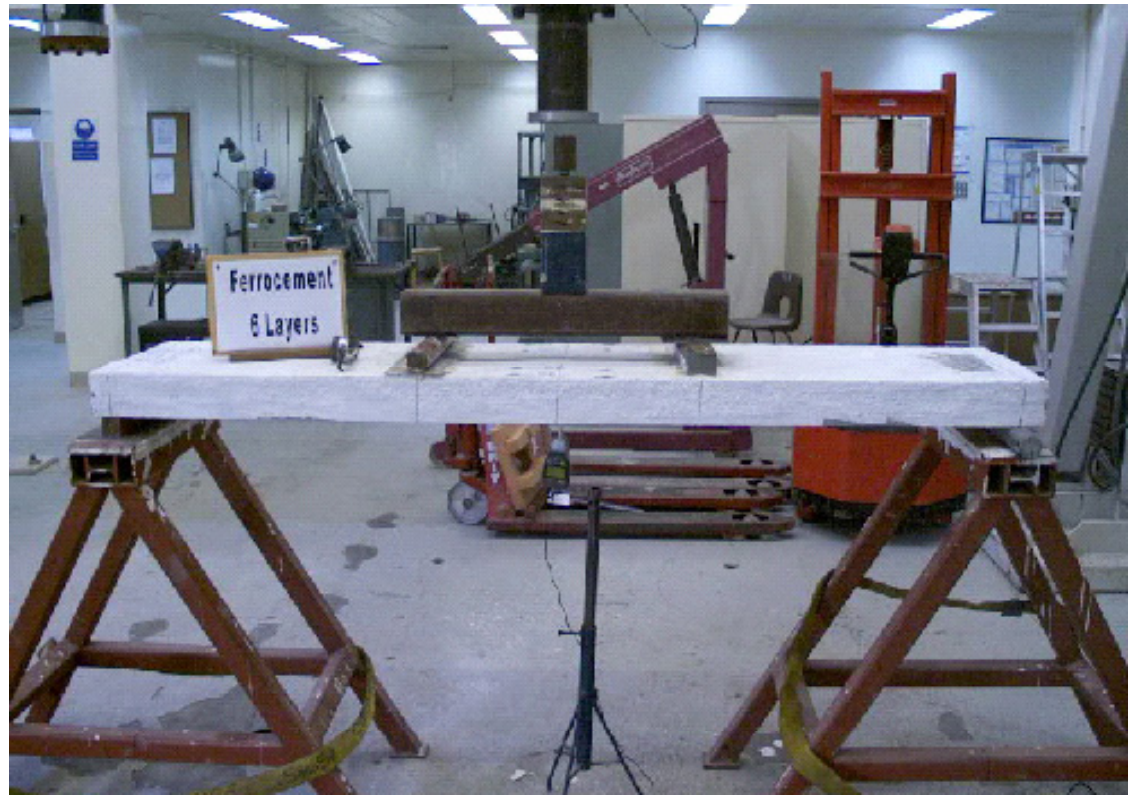

Figure 4: $\quad$ Test rig and typical panel tested.

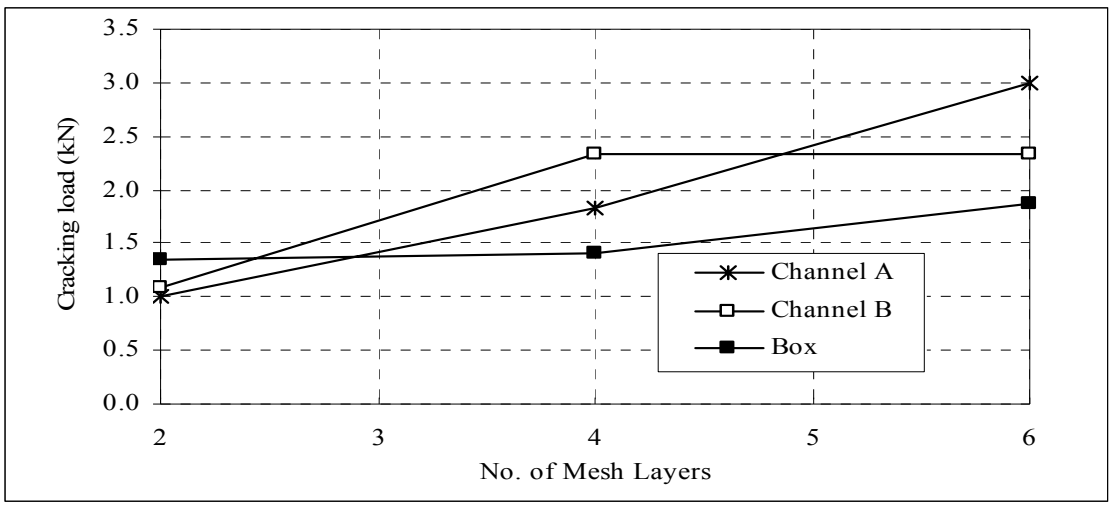

Figure 5: $\quad$ Cracking load.

\section{Experimental observation}

\subsection{Cracking load}

Figure 5 shows that all sections cracked at loads close to each other when the number of layers was 2. The box section cracking load was less than both channel sections when the number of layers was increased to 4 or 6 . In general, as the number of wire mesh increases the cracking load increases in all shapes. 


\subsection{Failure load}

The box section and channel A section had almost similar failure loads which were higher than the failure loads of channel B section for all number of layers as shown Figure 6. The ultimate load was increased with the increase of the wire mesh layers in all shapes. The increment was less pronounced in the case of channel B.

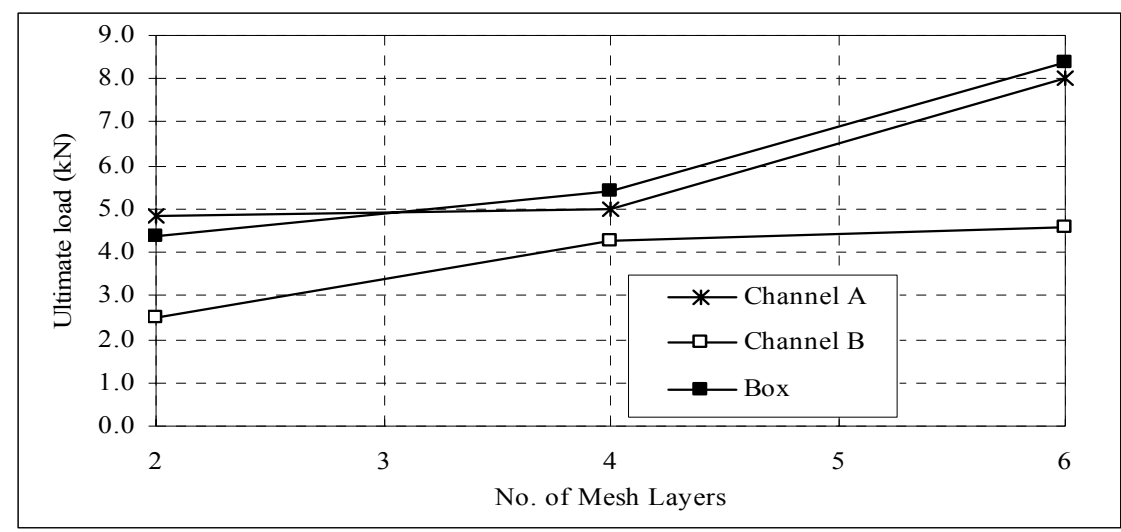

Figure 6: Failure load.

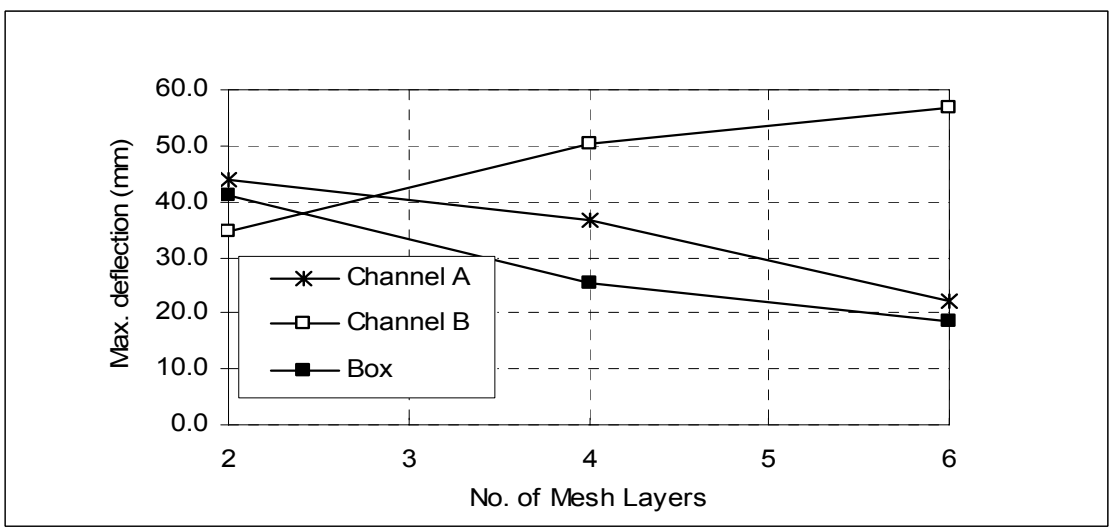

Figure 7: Maximum deflection.

\subsection{Deflection}

Figure 7 shows maximum vertical deflection at mid-span. It is clear that when the number of wire mesh layers was 2, all panels had close to each other deflection values. With exception to channel $\mathrm{B}$, the maximum deflection was decreased with the increase of the wire mesh layers from 2 to 4 and 6 . Figure 8 shows that, in all panels, as the number of wire mesh increases the deflection reduces for the same load. Figure 9 shows that there are no major differences in the behaviour of channel A and box section but channel B behaved in a softer manner, more deflection for same load. 


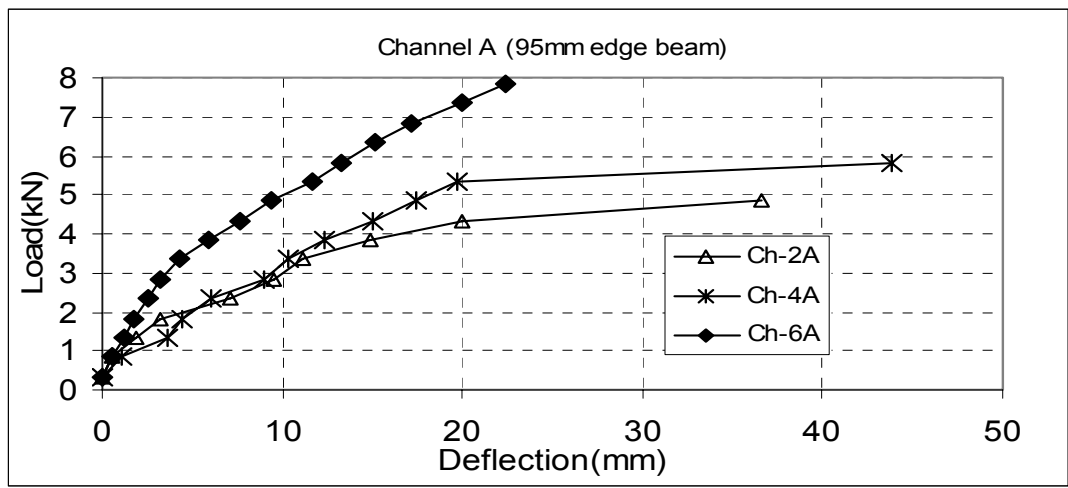

(a)

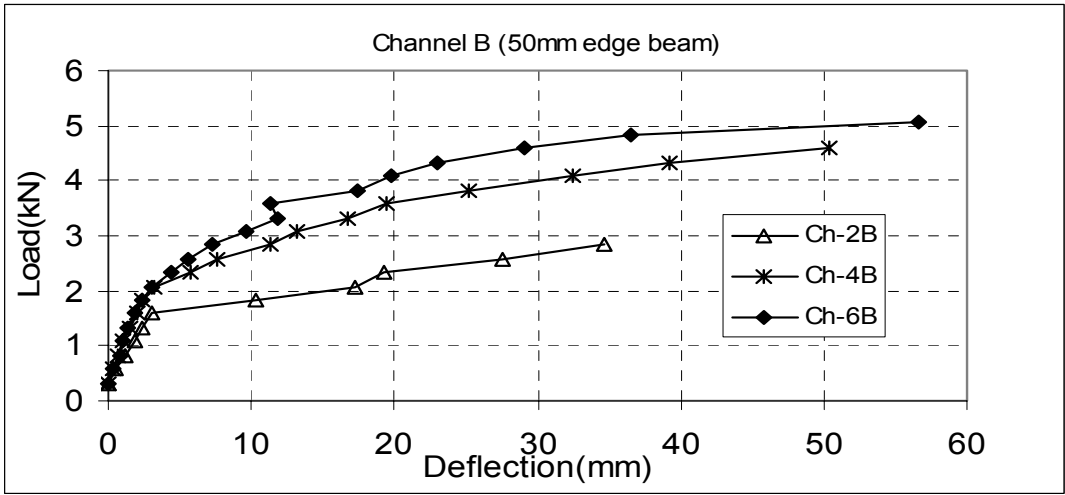

(b)

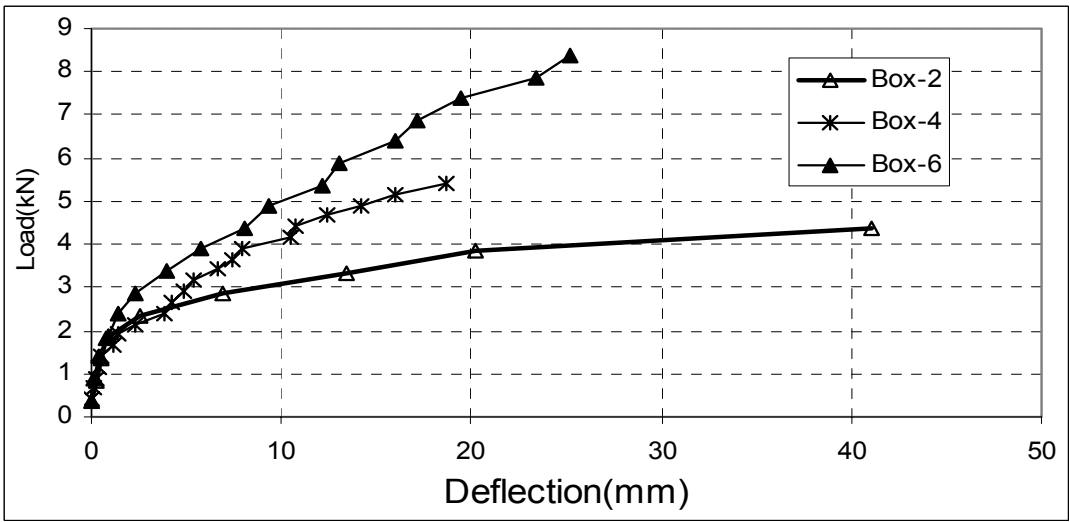

(c)

Figure 8: (a): Effect of the number of wire mesh layers on channel A deflection, (b): Effect of the number of wire mesh layers on channel B deflection, (c): Effect of the number of wire mesh layers on Box deflection. 


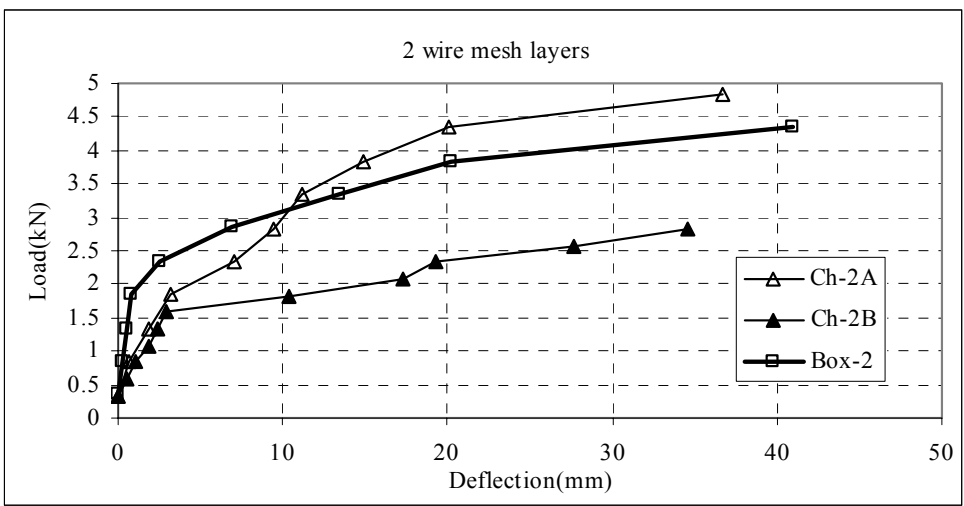

(a)

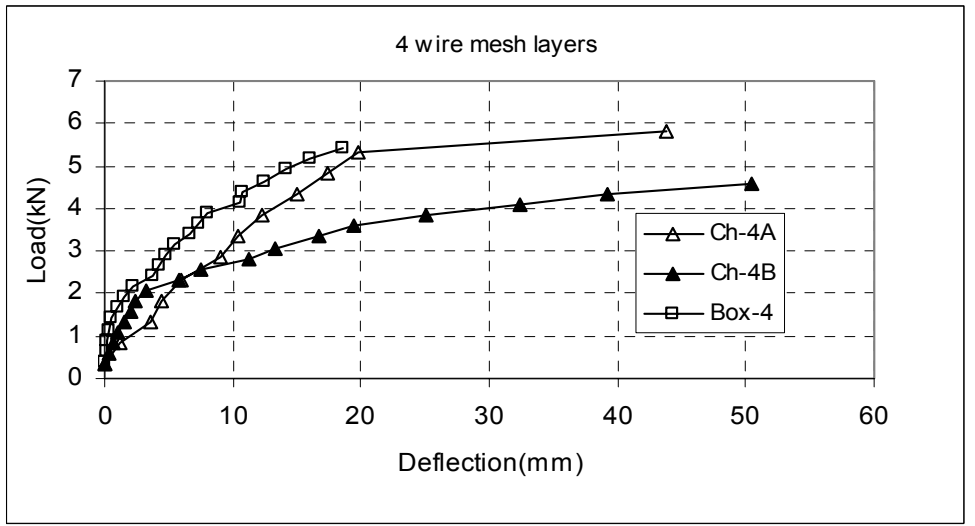

(b)

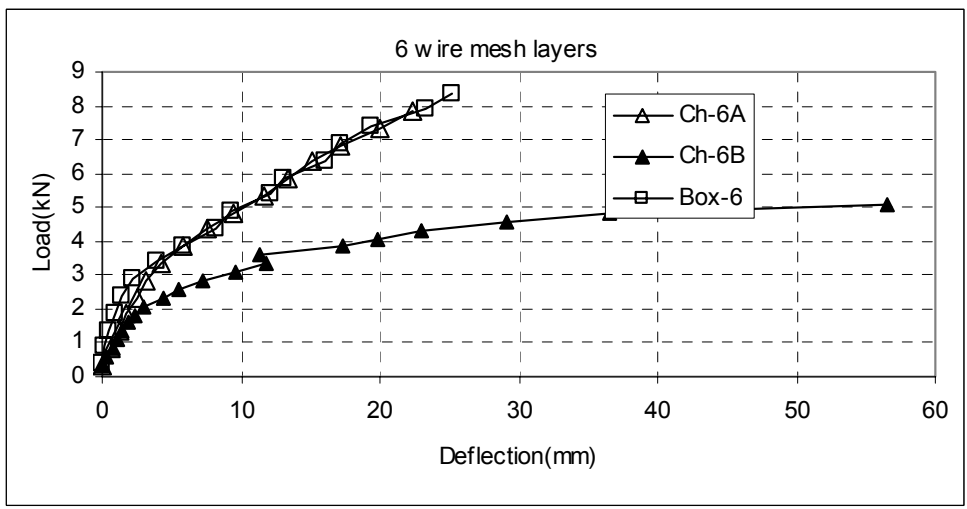

(c)

Figure 9: (a): Effect of shape on deflection with 2 wire mesh layers, (b): Effect of shape on deflection of panels with 4 wire mesh layers, (c): Effect of shape on deflection of panels with 6 wire mesh layers. 


\section{Conclusion}

Nine roof panels were tested for pure bending. Results from two types of channel sections, channel A and channel B, differing in the depth of the edge beam (95mm and $50 \mathrm{~mm})$ and one type of box section were compared. The number of wire mesh layers was varied from 2 to 6 . Results show that channel type A behaved in a similar way of the box section with close to each other failure loads and deflection while channel type B was softer regardless of the number of wire mesh layers. All panels showed acceptable cracking and failure load for roofing systems.

\section{References}

[1] Nedwell P.J and Swamy R.N., Ferrocement, St Edmundsbury Press, Bury St, Edmunds, Suffolk, 1994.

[2] Swamy R.N, Concrete Technology and design, Bell and Bain (Glasgow) Ltd, 1984.

[3] Al-Sulaimani, G.J., and Ahmad, S.F., Deflection and flexural rigidity of ferrocement I and Box beam. Journal of Ferrocement 18(1):1-12, 1988.

[4] Mathews, M.S., Sudhakumar, J. Sheela, S. and Seetharaman, P.R., Analytical and experimental investigations of hollow ferrocement roofing units, Journal of Ferrocement 21(1): 1-14, 1991.

[5] Kanai, S, and Brooks, J.J, Tensile, Flexual and Impact Behaviour of Ferrocement with chicken wire mesh reinforcement, Proceedings of the Fifth International Symposium on Ferrocement, UMIST, Manchester, pp.342-355, 1994.

[6] Mansour, M.A. and Paramasivan, P, Cracking behaviour and Ultimate strength of Ferrocement in flexure, Proceedings of the Second International Symposium on Ferrocement, Bangkok, Thailand, pp.47-59, 1985.

[7] Ahmed S.F., Saroash H. Lodi, and Juneid Qureshi, Shear behaviour of Ferrocement thin webbed sections, Cement and Concrete Research, Vol. 25, No. 5, pp.969-979, 1995.

[8] Al-Kubaisy, M.A. and Jummat, M.Z, Flexural behaviour of reinforced concrete slabs with Ferrocement tension zone cover, Journal of Construction and Building Materials, Vol 14, pp 245-252, 2000.

[9] Masood A., Arif M, Akhtar S. and Haquie M, Performance of Ferrocement panels in different environments, Cement and Concrete Research, Vol. 33, pp. 555-562, 2003.

[10] Hago, A.W., Al-Jabri, K.S., Al-Nuaimi, A.S., Al-Moqbali, H., and AlKubaisy, M.A, Ultimate and service behaviour of ferrocement roof slab panels, Construction and Building Materials 19:31-37, 2005. 